\title{
Breaking Haller's Rule: Brain-Body Size Isometry in a Minute Parasitic Wasp
}

\author{
Emma van der Woude ${ }^{a}$ Hans M. Smid $^{a}$ Lars Chittka $^{b}$ Martinus E. Huigens ${ }^{a}$ \\ ${ }^{\mathrm{a}}$ Laboratory of Entomology, Wageningen University, Wageningen, The Netherlands; ${ }^{\mathrm{b}}$ Queen Mary University of \\ London, Research Centre for Psychology, School of Biological and Chemical Sciences, London, UK
}

\section{Key Words}

Brain size $\cdot$ Allometry $\cdot$ Isometry $\cdot$ Miniaturization $\cdot$

Trichogramma evanescens

\begin{abstract}
Throughout the animal kingdom, Haller's rule holds that smaller individuals have larger brains relative to their body than larger-bodied individuals. Such brain-body size allometry is documented for all animals studied to date, ranging from small ants to the largest mammals. However, through experimental induction of natural variation in body size, and 3-D reconstruction of brain and body volume, we here show an isometric brain-body size relationship in adults of one of the smallest insect species on Earth, the parasitic wasp Trichogramma evanescens. The relative brain volume constitutes on average $8.2 \%$ of the total body volume. Brain-body size isometry may be typical for the smallest species with a rich behavioural and cognitive repertoire: a further increase in expensive brain tissue relative to body size would be too costly in terms of energy expenditure. This novel brain scaling strategy suggests a hitherto unknown flexibility in neuronal architecture and brain modularity.
\end{abstract}

Copyright $\odot 2013$ S. Karger AG, Basel

\section{KARGER}

E-Mail karger@karger.com

www.karger.com/bbe

\section{Introduction}

Across and within all animal species investigated so far, Haller's rule holds that smaller animals have proportionally larger brains than larger-bodied forms [Rensch, 1948]. In a double logarithmic plot, such an allometric brain-body size relationship is described by a straight line with a slope (the brain scaling coefficient $b$ ) lower than 1 . The lower $b$ is, the larger is the discrepancy in relative brain size between differently sized animals. Brain-body size allometries that have been reported to date range from a within-species $b=0.20$ for a tiny ant species to a between-species $b=0.77$ for mammals, with a tendency of within-species coefficients to be lower (fig. 1a) [Martin, 1981; Wehner et al., 2007; Riveros and Gronenberg, 2010; Eberhard and Wcislo, 2011; Seid et al., 2011]. In various species of ants, for example, intraspecific coefficients have been found to range between 0.20 and 0.40 , whereas the interspecific coefficient based on the mean brain and body mass of the same species is 0.57 [Wehner et al., 2007]. In very small animals, brain-body size allometry implies that brain size becomes a limiting factor of body miniaturization because costs for development and maintenance of energetically expensive brain tissue [Aiello and Wheeler, 1995] will become an excessively high bur- (c) 2013 S. Karger AG, Basel

0006-8977/13/0812-0086\$38.00/0
Emma van der Woude

Laboratory of Entomology, Wageningen University PO Box 8031

NL-6700 EH Wageningen (The Netherlands)

E-Mail emma.vanderwoude@wur.nl 

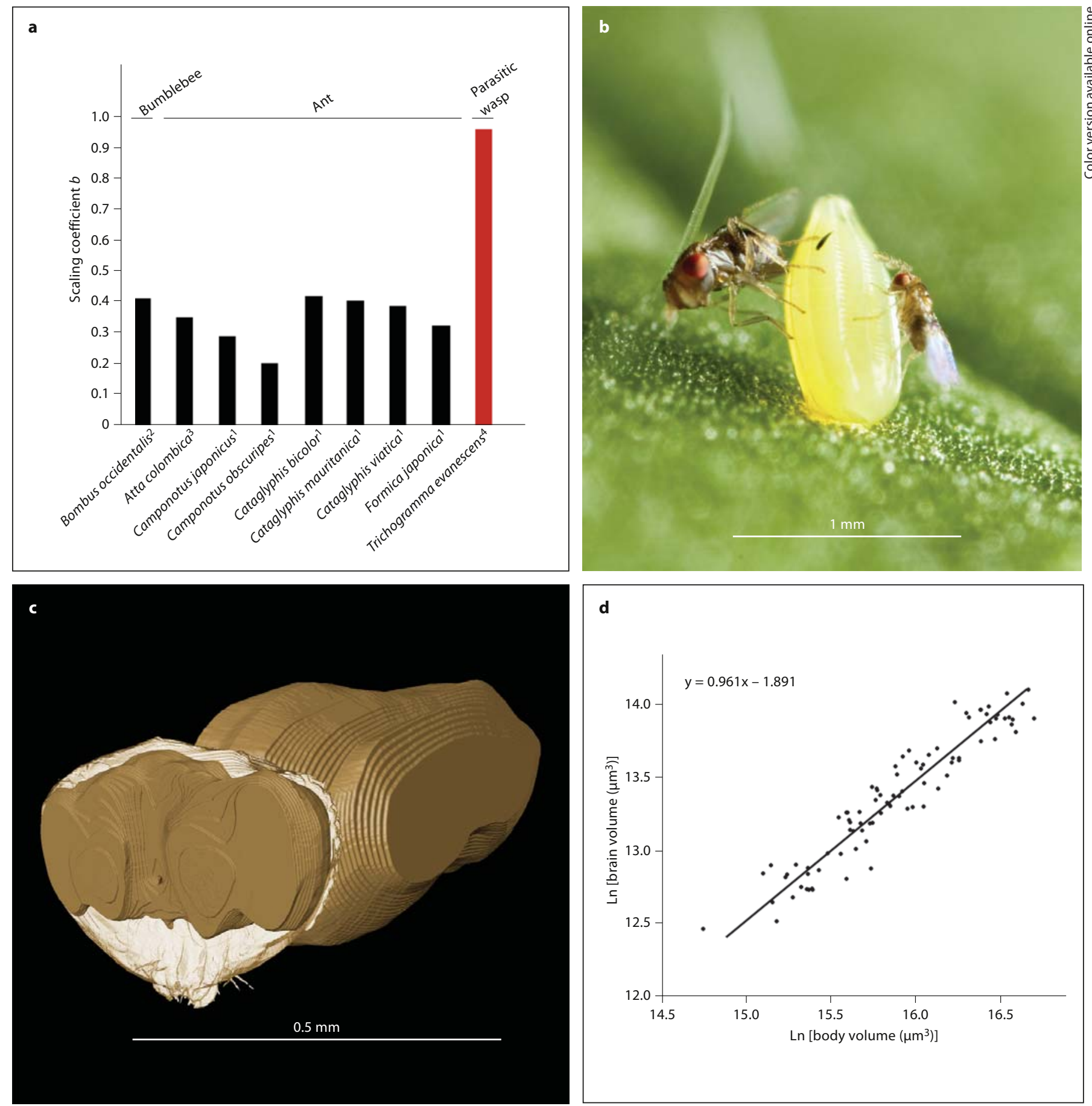

Fig. 1. Brain-body size relationship in T. evanescens wasps. a Allometric within-species brain scaling coefficients $b$ in insects. b Two phenotypically very different sized, but genotypically almost identical, T. evanescens sisters (from iso-female strain GD011) parasitizing an egg of the butterfly Pieris rapae (photo N.E. Fatouros, www.bugsinthepicture.com). c 3-D reconstruction of the brain and body volume of a female wasp using AMIRA software. $\mathbf{d}$ Double logarithmic plot of brain versus body volume, with the slope of the straight line representing the isometric coefficient $b=0.96\left(\mathrm{n}=87, \mathrm{r}^{2}=0.900\right) .{ }^{1}$ Data from Wehner et al. [2007]. ${ }^{2}$ Data from Riveros and Gronenberg [2010]. ${ }^{3}$ Data from Seid et al. [2011]. ${ }^{4}$ Data from this study. 


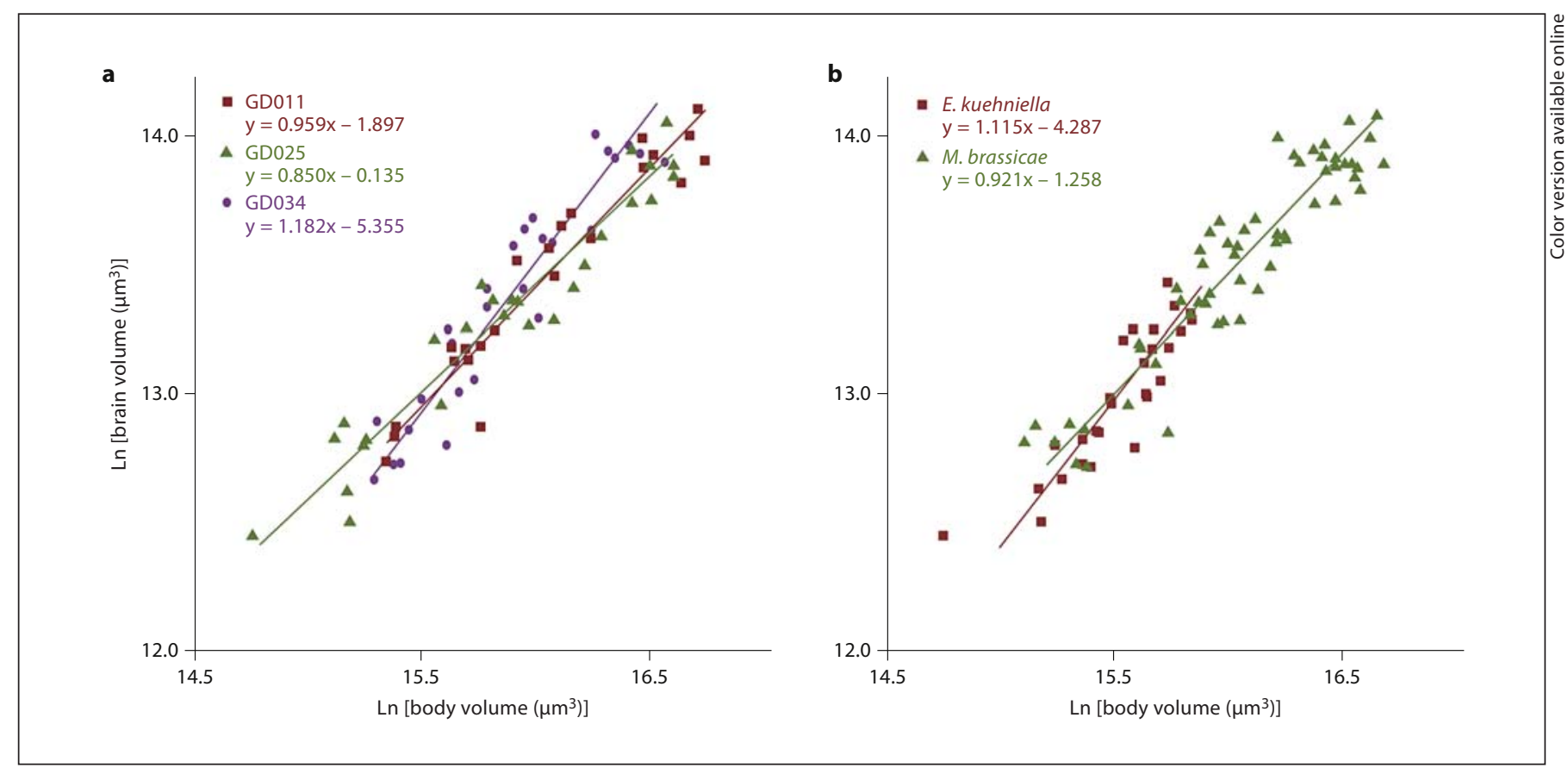

Fig. 2. Effect of genotype and host species on the brain-body volume relationship in T. evanescens wasps. a Wasps belonging to the three iso-female T. evanescens strains (genotypes) GD011 ( $\left.\mathrm{n}=29, \mathrm{r}^{2}=0.929\right)$, GD025 $\left(\mathrm{n}=29, \mathrm{r}^{2}=0.930\right)$ and GD034 $\left(\mathrm{n}=29, \mathrm{r}^{2}=0.894\right)$. $\mathbf{b}$ Wasps emerging from eggs of E. kuehniella $\left(\mathrm{n}=29, \mathrm{r}^{2}=\right.$ $0.797)$ or $M$. brassicae moths $\left(n=58, r^{2}=0.874\right)$. The slope of a straight line represents the brain scaling coefficient $b$.

den with increasing relative brain size [Kaas, 2000; Beutel et al., 2005; Grebennikov, 2008; Polilov and Beutel, 2009; Polilov, 2012].

In this study, we investigate the brain-body size relationship in minute ( $\pm 0.3-0.7-\mathrm{mm}$-long) parasitic Trichogramma evanescens wasps that complete their entire development inside eggs of butterflies and moths. Body volume can vary up to a factor 7 (see below) between genotypically identical wasps (fig. 1b, 2a), depending on the size of the host egg and the number of immatures developing inside it. Their brains are exquisitely miniaturized $(\varnothing=0.16-0.33 \mathrm{~mm})$ and are thus only marginally larger than a single pyramidal motor neuron (Betz cell) in the human brain [Rivara et al., 2003]. Nonetheless, the wasps' brains constitute a large proportion of the body volume (table 1). The extremely small brains of this species, however, does not seem to affect their behavioural performance. Female Trichogramma wasps, even the small phenotypes, display a rich behavioural and cognitive repertoire similar to much larger insects, including flight, walking, courtship, deciding over the size and sex of their progeny, vision, olfaction, learning and long- and short- term memory formation [Suzuki et al., 1984; Dutton and Bigler, 1995; Pompanon et al., 1997; Huigens et al., 2000, 2004, 2009, 2010, 2011; Keasar et al., 2000; Fatouros et al., 2005, 2008, 2012; Kruidhof et al., 2012]. For example, to find suitable host eggs in nature, even small female $T$. evanescens wasps that developed in small host eggs can learn to respond to pheromones emitted by mated (and thus egg-laying) female butterflies. The wasps mount butterflies and when they hitch a single ride on a mated female butterfly that leads to an oviposition into freshly laid butterfly eggs [Fatouros and Huigens, 2012], they learn to associate the butterfly's pheromones with the reward of fresh host eggs. After such a rewarding hitchhiking experience, the wasps form either shorter- or longerlasting memory depending on the reward value constituted by the butterfly eggs [Huigens et al., 2009, 2010; Kruidhof et al., 2012]. These complex behavioural traits are essential to find and parasitize suitable host eggs in nature and might require a certain, minimal brain size.

We hypothesized that $T$. evanescens has reached the limits of brain scaling so that smaller wasps cannot further reduce brain size without compromising brain per- 
Table 1. Scaling coefficients $b$ with confidence intervals and proxies for brain and body size in T. evanescens wasps depending on their genotype and the host species in which they developed

\begin{tabular}{|c|c|c|c|c|c|c|c|}
\hline & $\mathrm{n}$ & BodyL, $\mu \mathrm{m}$ & Brain $V, \mu \mathrm{m}^{3}$ & BodyV, $\mu \mathrm{m}^{3}$ & Rel. BrainV, \% & $b$ & $95 \%$ CI for $b$ \\
\hline \multicolumn{8}{|l|}{ Genotype } \\
\hline GD011 & 29 & $447 \pm 76^{\mathrm{a}}$ & $7.2 \pm 2.9 \times 10^{5 \mathrm{a}}$ & $9.3 \pm 4.1 \times 10^{6 \mathrm{a}}$ & $7.9 \pm 0.8^{\mathrm{a}}$ & $0.959^{\mathrm{a}}$ & $0.864-1.065^{* * *}$ \\
\hline GD025 & 29 & $448 \pm 91^{\mathrm{a}}$ & $6.8 \pm 2.9 \times 10^{5 \mathrm{a}}$ & $8.7 \pm 4.2 \times 10^{6 \mathrm{a}}$ & $8.2 \pm 1.2^{\mathrm{a}}$ & $0.850^{\mathrm{b}}$ & $0.766-0.943^{* * *}$ \\
\hline GD034 & 29 & $447 \pm 65^{\mathrm{a}}$ & $6.8 \pm 2.9 \times 10^{5 a}$ & $7.9 \pm 3.0 \times 10^{6 \mathrm{a}}$ & $8.5 \pm 1.2^{\mathrm{a}}$ & $1.182^{\mathrm{c}}$ & $1.040-1.344^{* * *}$ \\
\hline \multicolumn{8}{|l|}{ Host species } \\
\hline E. kuehniella & 29 & $390 \pm 38^{\mathrm{a}}$ & $4.7 \pm 1.2 \times 10^{5 \mathrm{a}}$ & $5.7 \pm 1.3 \times 10^{6 \mathrm{a}}$ & $8.2 \pm 1.0^{\mathrm{a}}$ & $1.115^{\mathrm{a}}$ & $0.934-1.331^{* * *}$ \\
\hline Total & 87 & $448 \pm 77$ & $6.9 \pm 2.9 \times 10^{5}$ & $8.6 \pm 3.8 \times 10^{6}$ & $8.2 \pm 1.2$ & 0.961 & $0.897-1.029^{* * *}$ \\
\hline
\end{tabular}

Means \pm standard deviations are given. ${ }^{\text {a-c }}$ Significant differences between genotypes or host species. ${ }^{* *} \mathrm{p}<0.001$. BodyL $=$ Body length; BrainV = brain volume; BodyV = body volume; Rel. BrainV = relative brain volume [(brain volume/body volume) $\times 100]$.

formance required for their complex parasitic lifestyle. In line with previous studies, we therefore expected to find a coefficient $b$ within or even lower than the $0.2-0.4$ range documented for tiny insect species (fig. 1a) [Wehner et al., 2007; Riveros and Gronenberg, 2010; Seid et al., 2011].

\section{Materials and Methods}

\section{Wasp Size Variation}

To determine the relationship between brain and body volume, female Trichogramma evanescens Westwood wasps (Hymenoptera: Trichogrammatidae) of three iso-female strains (the genotypes GD011, GD025 and GD034) were used. The three females that were used to initiate the strains were collected in 2006 from a cabbage field close to the city of Wageningen, The Netherlands. Since then, the strains were cultured in small host eggs of the Mediterranean flour moth Ephestia kuehniella in a climate room (22 $\pm 1{ }^{\circ} \mathrm{C}, 50-70 \% \mathrm{rh}, \mathrm{L} 16: \mathrm{D} 8$; developmental time from egg to adult wasp is \pm 11 days). Wasps of different sizes were reared by allowing female wasps to lay 1-2 eggs in E. kuehniella eggs (resulting in the smallest offspring) or to lay 1-5 eggs in larger host eggs of the cabbage moth Mamestra brassicae (table 1; fig. 2). To obtain the largest offspring, female wasps were given the opportunity to lay only one fertilized (female) egg in an M. brassicae egg by observing their ovipositing behaviour as described previously [Suzuki et al., 1984; Huigens et al., 2000; 2004]. The obtained variation in body size was representative of the variation in body size found in nature.

\section{Preparing Wasps for Confocal Laser Scanning Microscopy}

Wasps were fixed overnight in a mixture of $4 \%$ formaldehyde in $50 \%$ methanol in $0.1 \mathrm{M}$ phosphate buffer at neutral $\mathrm{pH}$ [Brandt et al., 2005]. Fixation was followed by rinsing 3 times in $70 \%$ ethanol and subsequent dehydration in graded series of ethanol (5 min of 90, 96 and twice in 100\% ethanol). Wasps were cleared in pure xylene for approximately $20 \mathrm{~min}$ and antennae, legs and wings were removed. Heads and bodies were separated and mounted in DePeX (Fluka) on the same microscope glass, with heads with the neck and bodies with the lateral part facing towards the coverslide [Brandt et al., 2005].

\section{Volume Measurements}

Objects were scanned with a Zeiss LSM 510 confocal laser scanning microscope using a 488-nm wavelength argon laser [Smid et al., 2003; Bleeker et al., 2006]. A Plan-Neofluar $\times 40$ oil immersion objective was used for the heads and a Plan-Apochromat $\times 10$ lens was used for the bodies. To correct for refractive index mismatch between the oil immersion lens and the dry lens, we used a correction factor of 1.6 for the $\mathrm{z}$-axis of the body preparations [Brandt et al., 2005]. Transparent properties of the cuticle allowed for complete scanning through the entire depth of the tissues. Digital image stacks were saved and analysed using AMIRA 5.3 software (Visage Imaging $\mathrm{GmbH}$ ) [Brandt et al., 2005]. Brains and bodies were traced using the segmentation editor and converted to labelled data sets. Parts of the optic lobes were invisible because of eye pigments; the inner linings of the cuticle in these regions were used as boundaries. Microtome sections of $T$. evanescens heads observed by conventional light microscopy confirmed that optic lobes were indeed tightly connected to the head capsule (not shown). Labelled data sets were subsequently converted to 3-D reconstructions (fig. 1c) and volumes were calculated by the material statistics option in the software. To calculate the entire body volume, the head volume was taken together with the volume of thorax and abdomen. Body length was measured from the start of the thorax to the tip of the abdomen with the 3-D line-measuring tool in AMIRA.

\section{Statistical Analysis}

The natural logarithms of brain volume and body volume were used to obtain the brain-body size relationship. Model II type regressions, i.e. (standardized) major axis, are more appropriate than linear regression for determining allometric relationships, in which both $\mathrm{x}$ and $\mathrm{y}$ values are measured with error. The aim of the model is to summarize the relationship instead of predicting 
values [Warton et al., 2006]. We used standardized (reduced) major axis regression because it produces confidence intervals with a higher precision than major axis regression. All regression analyses were performed in the SMATR package for R [Falster et al., 2006]. This software was used to calculate regression coefficients with confidence intervals, and to determine whether the slope of the regression line (the brain scaling component $b$ ) significantly deviated from 1 (isometric brain-body volume relationship) or not. Also, likelihood ratio analyses were performed to test for a common slope among regression lines of different genotypes and moth host species. When a common slope was found, SMATR was subsequently used to test for differences in elevation among the different regression lines. This determines the effect of genotype and host species on the brain-body volume relationship as ANCOVA does for linear regression [Warton et al., 2006]. We used an independent-samples Kruskal-Wallis test to compare body length, brain volume, body volume and relative brain volume between genotypes. An independent-samples Mann-Whitney U test was used to compare the same proxies for brain and body size between wasps developing from either E. kuehniella eggs or $M$. brassicae eggs. All statistical tests were performed at $\alpha=0.05$ in R 2.15.

\section{Results}

In our wasp sample, body length varied substantially (0.286-0.624 mm; table 1$)$. We found absolute body volume to vary by a factor of $7.01[2,522,829-17,688,651$ $\mu \mathrm{m}^{3}$, corresponding in theory (based on water) to a weight of $0.00025-0.0018 \mathrm{mg}$ ] whereas absolute brain volume varied by a factor of $5.14\left(257,547-1,326,117 \mu^{3}\right)$. Brain volume constituted on average $8.2 \%$ of body volume (table 1 ), with a maximum of $10.9 \%$, which is much greater than the $2.9 \%$ for another, even slightly smaller, trichogrammatid wasp species, Megaphragma mymaripenne (with a body length of $\pm 0.2 \mathrm{~mm}$ ) [Polilov, 2012]. Plotting brain volume against body volume after logarithmic transformation showed, in sharp contrast to what we expected, that $b$ was on average 0.96 (fig. 1d). This is, to the best of our knowledge, the highest such coefficient ever found in any animal taxon. This scaling coefficient $b$ is not significantly different from $1\left(\mathrm{r}_{85}=-0.126, \mathrm{p}=\right.$ 0.247 ), indicating an isometric relationship between brain and body size. Common slope tests revealed no significant deviations of the scaling coefficients of the different moth host species from the mean $b$ of $0.96\left(\chi_{1}^{2}=\right.$ $3.516, p=0.061$; fig. $2 b)$. This homogeneity of regression slopes allowed comparisons of elevations, which showed that moth host species did not significantly affect the brain-body volume relationship $\left(\chi_{1}^{2}=0.049, \mathrm{p}=0.825\right)$. There was a small, but significant difference in slopes between the three genotypes $\left(\chi_{2}^{2}=14.3, \mathrm{p}<0.001\right.$; fig. $\left.2 \mathrm{a}\right)$.
This implies that although the $b$ values of the three genotypes all approach 1 (ranging between 0.85 and 1.18; table 1), there is an effect of genotype on the brain-body size relationship.

\section{Discussion}

An isometric brain-body size relationship in extremely miniaturized animals with a rich sensory and behavioural repertoire, such as $T$. evanescens, is in contrast to what was expected from previous applications of Haller's rule. A trade-off between brain performance and the energetic costs of having a large brain may explain this: a further increase in relative brain size may be too costly for this wasp species in terms of energy expenditure [Aiello and Wheeler, 1995; Chittka and Niven, 2009; Navarrete et al., 2011]. Although very small beetles, strepsipterans and spiders can partially or completely relocate nervous tissue to other body parts to prevent the formation of an excessively large brain [Beutel et al., 2005; Polilov and Beutel, 2009; Eberhard and Wcislo, 2011; Quesada et al., 2011], this does not overcome the high energetic costs of maintaining a relatively large central nervous system (CNS). It therefore seems unlikely that $T$. evanescens displays a strong allometric relationship between whole CNS size and body size, even though such CNS-body size allometries were recently found for orbweaving and cleptoparasitic spiders [Quesada et al., 2011].

We used iso-female strains to reduce genotypic variation that might obscure the brain-body size relationship. It is unlikely that the use of these iso-female strains caused the isometric relationship found in this study, because genes that affect the structure of the brain would be expected to determine the numbers and morphology of all neurons in the brain, which ultimately would result in a brain of a certain absolute size. Thus, a fixed genotype would be expected to determine a more constant absolute brain size. The unique variation that we found in absolute but not in relative brain size within a genotype can only be explained by a yet unknown flexibility in size, morphology and/or number of neurons, and potentially even in brain modularity (compartmentalisation) [Kaas, 2000]. This suggests the presence of specific plasticity genes that facilitate an unusually high level of plasticity in neuron numbers and/or neuron properties.

A recent estimate suggests that the adult brain of $T$. evanescens has 37,000 nucleated neurons [Polilov, 2012], 8 times more than the approximately 4,600 neurons in the adult brain (and $\pm 7,400$ in the whole CNS) of a re- 
lated parasitic wasp species, M. mymaripenne. In that study by Polilov [2012], it was estimated that the brain volume of $M$. mymaripenne was on average $\pm 13 \times$ smaller than in T. evanescens (corresponding body size of $T$. evanescens not known), suggesting that the average volume per neuron was higher in T. evanescens. Of these 4,600 neurons in the brain of $M$. mymaripenne, however, approximately $95 \%$ were anucleate neurons, of which the somata were almost twice as small as those of the $(<300)$ nucleated neurons in the adult brain [Polilov, 2012]. This suggests that nucleated neurons must be relatively small in T. evanescens when compared to nucleated neurons of other insects, including M. mymaripenne. A benefit of smaller neurons over larger ones is that they are energetically less expensive both at rest and whilst signaling [Niven and Laughlin, 2008], and may be packed more densely [Beutel et al., 2005]. Biophysical theory and stochastic simulations indicate that neurite diameter can, however, not be reduced much below $0.1 \mu \mathrm{m}$ because channel noise would disrupt communication [Faisal et al., 2005]. The smallest diameters of neuron cell bodies documented for minute insects so far are $2-3 \mu \mathrm{m}$, possibly because neuron cell body diameter is restricted by the size of the nucleus [Grebennikov, 2008; Eberhard and Wcislo, 2011; Quesada et al., 2011]. Interestingly, adult $M$. mymaripenne seem to have solved the latter problem by having anucleate neurons [Polilov, 2012]. The question of whether such anucleate neurons are as functional as nucleate neurons remains.

In conclusion, the isometric brain-body size relation found in T. evanescens suggests a strong constraint on the upper limit of relative brain size in extremely miniaturized insects. This is most likely an energetic limitation that determines a constant, relative brain size by preventing an increase in the brain-body size ratio in the smallest individuals. Since their complex behaviour sets a strong constraint on minimal cognitive performance as well, we expect that specific genes have evolved to facilitate extreme plasticity in absolute brain size by adjusting the number and/or properties of neurons. The use of tiny parasitic wasps that display brain isometry and a large variation in body size provides unique opportunities to study physical constraints on the smallest dimensions of neurons and adaptations in brain modularity, and the consequences on behaviour.

\section{Acknowledgements}

We thank Léon Westerd, Frans van Aggelen and André Gidding for insect rearing. This work was supported by NWO/ALW open competition grant 820.01.012 (to H.M.S.) and PE\&RC grant 31.840.10154 (to E.W.).

\section{References}

Aiello LC, Wheeler P (1995): The expensive-tissue hypothesis: the brain and the digestive system in human and primate evolution. Curr Anthropol 36:199-221.

Beutel RG, Pohl H, Hunefeld F (2005): Strepsipteran brains and the effect of miniaturization (Insecta). Arthropod Struct Dev 34: 301-313.

-Bleeker MAK, van der Zee B, Smid HM (2006): Octopamine-like immunoreactivity in the brain and suboesophageal ganglion of two parasitic wasps, Cotesia glomerata and Cotesia rubecula. Anim Biol 56:247-275.

- Brandt R, Rohlfing T, Rybak J, Krofczik S, Maye A, Westerhoff M, Hege HC, Menzel R (2005): Three-dimensional average-shape atlas of the honeybee brain and its applications. J Comp Neurol 492:1-19.

Chittka L, Niven JE (2009): Are bigger brains better? Curr Biol 19:R995-R1008.

Dutton A, Bigler F (1995): Flight activity assessment of the egg parasitoid Trichogramma brassicae (Hym.: Trichogrammatidae) in laboratory and field conditions. Entomophaga 40:223-233.

\footnotetext{
Eberhard WG, Wcislo WT (2011): Grade changes in brain-body allometry: morphological and behavioural correlates of brain size in miniature spiders, insects and other invertebrates; in Casas J (ed): Advances in insect physiology. Burlington, Academic Press Burlington, pp 155-214.

Faisal AA, White JA, Laughlin SB (2005): Ionchannel noise places limits on the miniaturization of the brain's wiring. Curr Biol 15: 1143-1149.

Falster DS, Warton DI, Wright IJ (2006): SMATR: Standardised Major Axis Tests and Routines, version 2.0. http://www.bio. mq.edu.au/ecology/SMATR/.

- Fatouros NE, Broekgaarden C, Bukovinszkine' Kiss G, van Loon JJA, Mumm R, Huigens ME, Dicke M, Hilker M (2008): Male-derived butterfly anti-aphrodisiac mediates induced indirect plant defense. Proc Natl Acad Sci USA 105:10033-10038.

Fatouros NE, Huigens ME (2012): Phoresy in the field: natural occurrence of Trichogramma egg parasitoids on butterflies and moths. BioControl 57:493-502.
}

Fatouros NE, Huigens ME, van Loon JJA, Dicke M, Hilker M (2005): Chemical communication: butterfly anti-aphrodisiac lures parasitic wasps. Nature 433:704.

Fatouros NE, Lucas-Barbosa D, Weldegergis BT, Pashalidou FG, van Loon JJA, Dicke M, Harvey JA, Gols R, Huigens ME (2012): Plant volatiles induced by herbivore egg deposition affect insects of different trophic levels. PLoS One 7:e43607.

Grebennikov VV (2008): How small can you go: factors limiting body miniaturization in winged insects with a review of the pantropical genus Discheramocephalus and description of six new species of the smallest beetles (Pterygota: Coleoptera: Ptiliidae). Eur J Entomol 105:313-327.

Huigens ME, de Almeida RP, Boons PAH, Luck RF, Stouthamer R (2004): Natural interspecific and intraspecific horizontal transfer of parthenogenesis-inducing Wolbachia in Trichogramma wasps. Proc Biol Sci 271:509515. 
Huigens ME, de Swart E, Mumm R (2011): Risk of egg parasitoid attraction depends on antiaphrodisiac titre in the large cabbage white butterfly Pieris brassicae. J Chem Ecol 37: 364-367.

-Huigens ME, Luck RF, Klaassen RH, Maas MFPM, Timmermans MJ, Stouthamer R (2000): Infectious parthenogenesis. Nature 405:178-179.

Huigens ME, Pashalidou FG, Qian MH, Bukovinszky T, Smid HM, Van Loon JJ, Dicke M, Fatouros NE (2009): Hitch-hiking parasitic wasp learns to exploit butterfly anti-aphrodisiac. Proc Natl Acad Sci USA 106:820-825.

Huigens ME, Woelke JB, Pashalidou FG, Bukovinszky T, Smid HM, Fatouros NE (2010): Chemical espionage on species-specific butterfly anti-aphrodisiacs by hitchhiking Trichogramma wasps. Behav Ecol 21:470478.

Kaas J (2000): Why is brain size so important: design problems and solutions as neocortex gets bigger or smaller. Brain Mind 1:7-23.

- Keasar T, Ney-Nifle M, Mangel M (2000): Evidence for learning of visual host-associated cues in the parasitoid wasp Trichogramma thalense. Israel J Zool 46:243-247.

-Kruidhof HM, Pashalidou FG, Fatouros NE, Figueroa IA, Vet LE, Smid HM, Huigens ME (2012): Reward value determines memory consolidation in parasitic wasps. PLoS One 7:e39615.
Martin RD (1981): Relative brain size and basic metabolic rate in terrestrial vertebrates. $\mathrm{Na}$ ture 293:57-60.

Navarrete A, van Schaik CP, Isler K (2011) Energetics and the evolution of human brain size. Nature 480:91-93.

Niven JE, Laughlin SB (2008): Energy limitation as a selective pressure on the evolution of sensory systems. J Exp Biol 211:1792-1804.

Polilov AA (2012): The smallest insects evolve anucleate neurons. Arthropod Struct Dev 41: 29-34.

Polilov AA, Beutel RG (2009): Miniaturization effects in larvae and adults of Mikado sp. (Coleoptera, Ptiliidae), one of the smallest free-living insects. Arthropod Struct Dev 38: 247-270.

Pompanon F, De Schepper B, Mourer Y, Fouillet P, Bouletreau M (1997) Evidence for a substrate-borne sex pheromone in the parasitoid wasp Trichogramma brassicae. J Chem Ecol 23:1349-1360.

-Quesada R, Triana E, Vargas G, Douglass JK, Seid MA, Niven JE, Eberhard WG, Wcislo WT (2011): The allometry of CNS size and consequences of miniaturization in orbweaving and cleptoparasitic spiders. Arthropod Struct Dev 40:521-529.

Rensch B (1948): Histological change with evolutionary changes of body size. Evolution 2 : 218-230.
Rivara C-B, Sherwood CC, Bouras C, Hof PR (2003): Stereologic characterization and spatial distribution patterns of Betz cells in the human primary motor cortex. Anat Rec 270A:137-151.

Riveros AJ, Gronenberg W (2010): Brain allometry and neural plasticity in the bumblebee Bombus terrestris. Brain Behav Evol 75:138148.

Seid MA, Castillo A, Wcislo WT (2011): The allometry of brain miniaturization in ants. Brain Behav Evol 77:5-13.

Smid HM, Bleeker MA, van Loon JJ, Vet LE (2003): Three-dimensional organization of the glomeruli in the antennal lobe of the parasitoid wasps Cotesia glomerata and C. rubecula. Cell Tissue Res 312:237-248.

Suzuki Y, Tsuji H, Sasakawa M (1984): Sex allocation and effects of superparasitism on secondary sex ratios in the gregarious parasitoid, Trichogramma chilonis (Hymenoptera: Trichogrammatidae). Anim Behav 32:78484

Warton DI, Wright IJ, Falster DS, Westoby M (2006): Bivariate line-fitting methods for allometry. Biol Rev 81:259-291.

Wehner RT, Fukushi T, Isler K (2007): On being small: brain allometry in ants. Brain Behav Evol 69:220-228. 